\title{
Polymeric Foams as the Matrix of Voltammetric Sensors for the Detection of Catechol, Hydroquinone, and Their Mixtures
}

\author{
C. Fernandez-Blanco, ${ }^{1}$ M. Mugica, ${ }^{2}$ M. A. Rodriguez-Perez, ${ }^{2}$ C. Garcia-Cabezón, ${ }^{1}$ \\ and $M$. L. Rodriguez-Mendez $\mathbb{1}^{1}$ \\ ${ }^{1}$ GroupUVaSens, Department of Inorganic Chemistry, Engineers School, Universidad de Valladolid, Valladolid, Spain \\ ${ }^{2}$ Cellular Materials Laboratory (CellMat), Condensed Matter Physics Department, University of Valladolid, Campus Miguel Delibes, \\ Paseo de Belén n7, Valladolid, Spain
}

Correspondence should be addressed to M. L. Rodriguez-Mendez; mluz@eii.uva.es

Received 2 February 2018; Accepted 29 April 2018; Published 21 May 2018

Academic Editor: Andrea Cusano

Copyright (c) 2018 C. Fernandez-Blanco et al. This is an open access article distributed under the Creative Commons Attribution License, which permits unrestricted use, distribution, and reproduction in any medium, provided the original work is properly cited.

\begin{abstract}
Porous electrodes based on polymethylmethacrylate and graphite foams (PMMA_G_F) have been developed and characterized. Such devices have been successfully used as voltammetric sensors to analyze catechol, hydroquinone, and their mixtures. The presence of pores induces important changes in the oxidation/reduction mechanism of catechol and hydroquinone with respect to the sensing properties observed in nonfoamed PMMA_graphite electrodes (PMMA_G). The electropolymerization processes of catechol or hydroquinone at the electrode surface observed using PMMA_G do not occur at the surface of the foamed PMM_G_F. In addition, the limits of detection observed in foamed electrodes are one order of magnitude lower than the observed in the nonfoamed electrodes. Moreover, foamed electrodes can be used to detect simultaneously both isomers and a remarkable increase in the electrocatalytic properties shown by the foamed samples, produces a decrease in the oxidation potential peak of catechol in presence of hydroquinone, from $+0.7 \mathrm{~V}$ to $+0.3 \mathrm{~V}$. Peak currents increased linearly with concentration of catechol in presence of hydroquinone over the range of $0.37 \cdot 10^{-3} \mathrm{M}$ to $1.69 \cdot 10^{-3} \mathrm{M}$ with a limit of detection (LOD) of $0.27 \mathrm{mM}$. These effects demonstrate the advantages obtained by increasing the active surface by means of porous structures.
\end{abstract}

\section{Introduction}

The assessment of antioxidants in foods is of great importance due to the health benefits associated to their intake, to their influence in the organoleptic characteristics of foods and beverages, and to their role in their preservation. Catechol (1,2-dihydroxybenze, CT) and hydroquinone (1,4dihydroxybenze, HQ) are two dihydroxybenzene isomers that occur naturally in many plant foods (onions, coffee, tea leaves, etc.) and beverages such as wines [1].

Simultaneous detection of dihydroxybenzene isomers as $\mathrm{CT}$ and HQ is difficult because they have similar structure and characteristics. The main methods for the determination of CT and HQ mixtures are high-performance liquid chromatography (HPLC) [2-5], gas chromatography coupled with mass spectrometry $[5,6]$, spectrophotometry [7-9], fluorescence $[10,11]$, chemiluminescence [12-14], or capillary electrochromatography $[15,16]$. Among all these techniques, electrochemical methods represent an advantage due to their low price, high sensitivity, short experimental times, and portability $[17,18]$.

The simultaneous assessment of CT and HQ at conventional carbon electrodes is difficult because their similar chemical structures lead to resembling responses which produce an overlap of their redox peaks [19-21]. In order to overcome this problem, electrodes have been chemically modified with many materials such as activated glassy carbon [22], modified electrodes with graphene [18, 23-26], carbon nanoparticles [27], carbon nanofibers [28, 29], carbon nanotubes [30], or gold nanoparticles [29, 31].

In addition, electrodes can be modified using different techniques, leading to electrodes with distinct characteristics 
which depend (among other factors) in the number of active sites at the electrode surface. Thus, the sensitivity and limits of detection can be improved by increasing the number of active sites at the electrode surface. Different strategies can be used to increase the number of active sites such as the use of layered hydroxide films [24], mesoporous materials [25], or nanostructured sensing layers [32, 33]. A different approach could be to use foamed materials as the sensing element. Recently, foams from metals like nickel [34-36] or copper [37-39] have been developed to obtain efficient electrochemical sensors. These electrodes show a high specific active surface, but they are not ideal materials to fabricate electrodes because they have redox activity. Foamed carbon materials are also good candidates, but the electrodes are fragile.

Our group proposes here a new class of foamed electrodes based on a polymeric matrix. The reason is that polymeric foams are easy to obtain and the pore size and structure can be easily controlled. In addition, their conductivity can be improved by doping the foam with a carbonaceous material. In particular, in this work, a composite foam formed by a polymeric matrix of polymethylmethacrylate (PMMA) and graphite as the conductive additive is developed here using the gas dissolution foaming method in which the saturation temperature, foaming temperature, and saturation pressure are controlled parameters during the foaming process [40]. The obtained foams have been employed as electrochemical sensors for the detection of CT and HQ which are two phenols of high interest for food industry. The dynamic properties of the electrodes and the limits of detection have been evaluated. The possibility of distinguishing these similar isomers has been analyzed.

\section{Materials and Methods}

2.1. Chemicals. Polymethylmethacrylate (PMMA) V 825T was kindly supplied by ALTUGLAS $^{\circledR}$ International (Colombes, France) in the form of pellets. The material used presents a density $(\rho)$ of $1.19 \mathrm{~g} \cdot \mathrm{cm}^{-3}$ (measured at $23^{\circ} \mathrm{C}$ and $50 \% \mathrm{HR}$ ) and a glass transition temperature ( $\mathrm{Tg}$ ) of $114.5^{\circ} \mathrm{C}$ measured by differential scanning calorimetry (DSC). Medical grade $\mathrm{CO}_{2}$ (99.9\% purity) was used as blowing agent.

Catechol (CT), hydroquinone (HQ), and $\mathrm{KCl}$ were purchased from Sigma-Aldrich, and graphite (G) (>99\%) was purchase from Fluka. Chloroform stabilized with ethanol was purchased from Scharlab. All chemicals were used as received. Aqueous solutions were prepared using highquality water (resistivity of $18.2 \mathrm{M} \Omega \cdot \mathrm{cm}^{-1}$ ) from a Milli-Q system (Millipore, Billerica, MA, USA).

2.2. Sensor Preparation. 1.4 g of PMMA was dissolved in $32 \mathrm{~mL}$ of hot chloroform $\left(50^{\circ} \mathrm{C}\right)$. Then, the solution was placed in a Petri dish to evaporate the solvent until a PMMA film was obtained.

Working in a similar way, films of PMMA/graphite (2/1) were prepared. Previously, the mixture was homogenized using a sonicator probe (Vibra Cell sonics) to get a good dispersion of graphite in the PMMA solution. This PMMA/ graphite ratio was chosen according to preliminary experiments that showed that using lower amounts of graphite did not produce enough conductivity to be used as sensitive material.

Foamed samples were produced in a high pressure vessel (model PARR 4681) provided by Parr Instrument Company (Moline, IL, USA). The pressure system comprises an accurate pressure pump controller (model SFT-10) provided by Supercritical Fluid Technologies Inc. With this set-up, a set of foaming experiments has been performed through the so-called gas dissolution foaming process. This process consists of two basic steps. The first one is the saturation of the polymeric sample with gas under high pressure. In this step, the gas reaches an equilibrium concentration when given enough time for diffusion of gas into the polymer, giving rise to a gas-polymer system. In the second step, bubbles are nucleated in the gas-polymer system by means of a thermodynamic instability which, in this specific case, can be obtained by a sudden drop in pressure [41]. The foaming experiments have been performed by a single-step foaming process [40] to prevent fast diffusion of the gas during the extraction of the polymer films from the autoclave after saturation. In this process, the gas saturation temperature is higher than the $\mathrm{T}_{\mathrm{g}, \mathrm{ef}}$ of the polymer (which is in a rubbery state), allowing the gas expansion during the pressure release. Hence, the samples are already foamed when extracted from the pressure vessel. In these tests, the saturation pressure has been set at $30 \mathrm{MPa}$. Saturation temperature and saturation time were fixed at $50^{\circ} \mathrm{C}$ and $24 \mathrm{~h}$. After saturation, the pressure was released at a high depressurization rate $(90 \mathrm{MPa} / \mathrm{s})$ by means of an electrovalve.

Moreover, gas diffusion can provoke heterogeneous cellular structures in the samples even on the single-step foaming method. Consequently, films have been confined in a mold consisting of two aluminum frames (Figure 1), restricting $\mathrm{CO}_{2}$ surface diffusion and increasing the gas availability for cell nucleation and growth [42]. The mold was closed by means a torque wrench so as the screws reach the same tighten level, achieving the desired constrainment effect.

2.3. Structure Characterization by SEM. A scanning electron microscope (Quanta 200 FEG, Hillsboro, OR, USA) was used to obtain images of both the surface and the inner structure of the foams. Images of the surface were obtained by covering the surface with gold using a sputter coater (model SDC 005, Balzers Union, Balzers, Liechtenstein). Images of the inner structure were obtained by fracturing the samples: samples were cooled down with liquid nitrogen and then fractured and coated with gold using a sputtering.

2.4. Electrochemical Measurements. Electrochemical experiments were carried out using a PARSTAT 2273 potentiostat/galvanostat (AMETEK scientific instrument) in a three-cell configuration. A platinum foil with a size of $2 \mathrm{~cm} \times 1 \mathrm{~cm}$ and a $\mathrm{Ag} / \mathrm{AgCl} / \mathrm{KCl} 3 \mathrm{M}$ electrode was used as counter electrode and reference electrode, respectively. PMMA samples were used as the working electrode including a PMMA film (PMMA), a PMMA foam (PMMA_F), a PMMA film doped with graphite (2/1), which is denoted as 


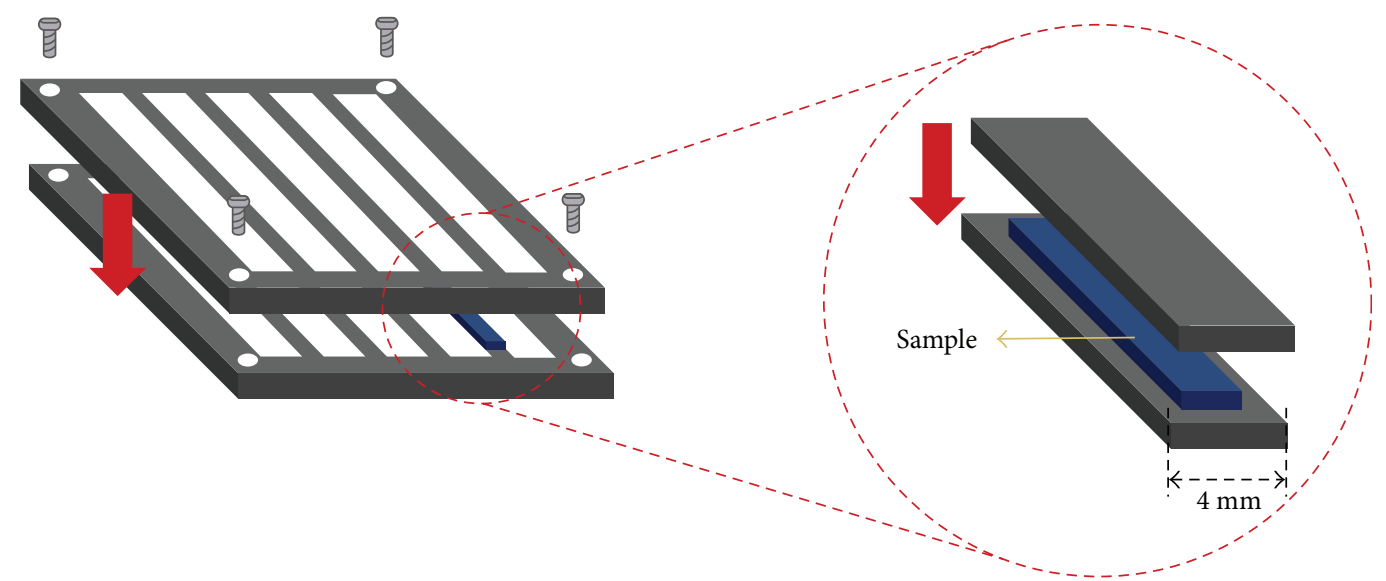

FIgURe 1: Aluminum frame used to constrain the films during the foaming tests.

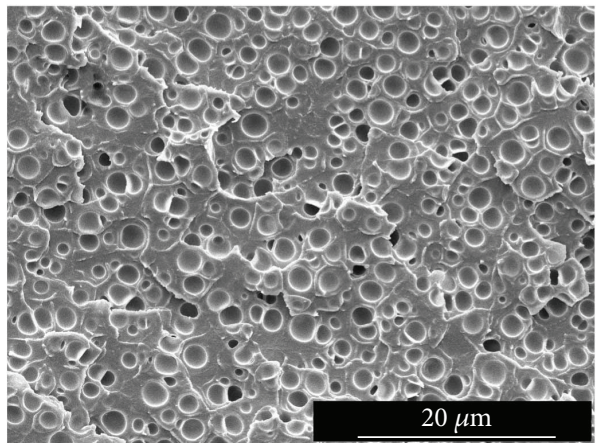

(a)

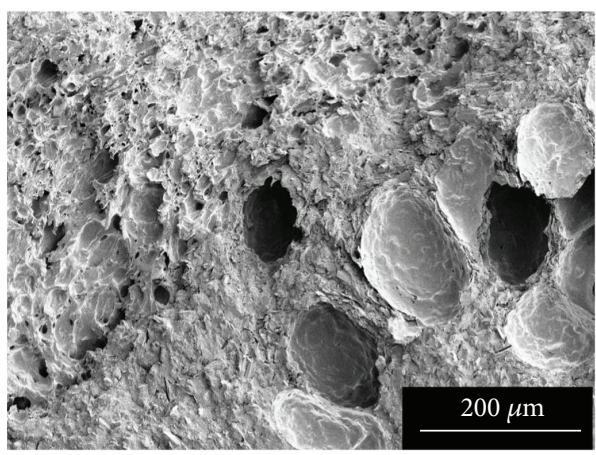

(c)

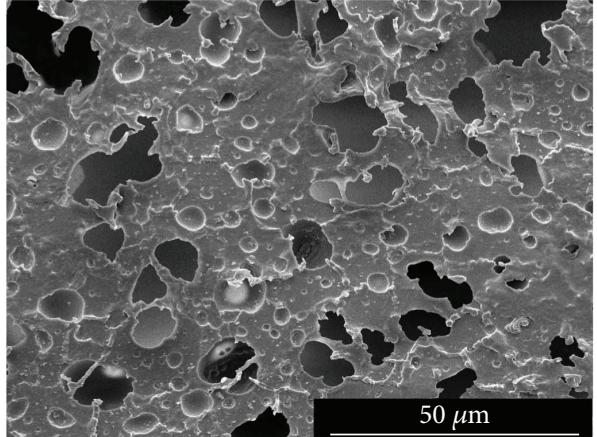

(b)

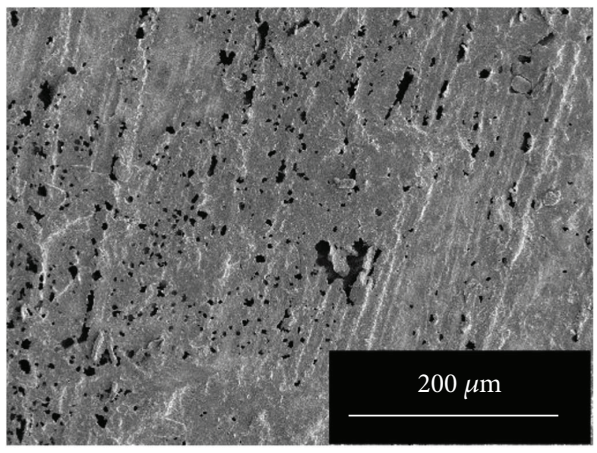

(d)

Figure 2: SEM images of (a) PMMA_F inner structure, (b) PMMA_F surface structure, (c) PMMA_F_G inner structure, and (d) PMMA_F_G surface structure.

PMMA_G, and a PMMA foam doped with graphite $(2 / 1)$ which is denoted as PMMA_F_G.

Electrochemical impedance spectroscopy (EIS) was carried out in a $0.1 \mathrm{M} \mathrm{KCl}$ solution with a frequency range from $31600 \mathrm{~Hz}$ to $0.1 \mathrm{~Hz}$ with signal amplitude of $10 \mathrm{mV}$ at a working potential of $0.0 \mathrm{~V}$.

Square wave voltammetry was used for studying the response for our sensors towards phenols. The reason to use this technique is that it reduces the faradaic current, producing lower limits of detection than cyclic voltammetry [43]. Calibration curves were built using square wave voltammetry (SWV) as electrochemical technique from $-0.6 \mathrm{~V}$ to $+1.0 \mathrm{~V}$ at a scan rate of $50 \mathrm{mV} / \mathrm{s}$ with an amplitude pulse of $50 \mathrm{mV}$, a duration of pulse of $0.02 \mathrm{~s}$, and a step height of $2 \mathrm{mV}$. Dynamic properties were evaluated carrying out a cyclic voltammetry in a $0.1 \mathrm{M}$ of $\mathrm{KCl}$ solution that contains $10^{-3} \mathrm{M}$ of CT from $-0.5 \mathrm{~V}$ to $+1.5 \mathrm{~V}$ for increasing scan rates (from $0.1 \mathrm{~V} / \mathrm{s}$ to $0.3 \mathrm{mV} / \mathrm{s}$ ).

\section{Results and Discussion}

3.1. Structural Characterization of the Electrodes. In a first step, both the internal and the surface structure of the foamed samples were characterized using Scanning Electron Microscope (SEM). This information was used to evaluate the 


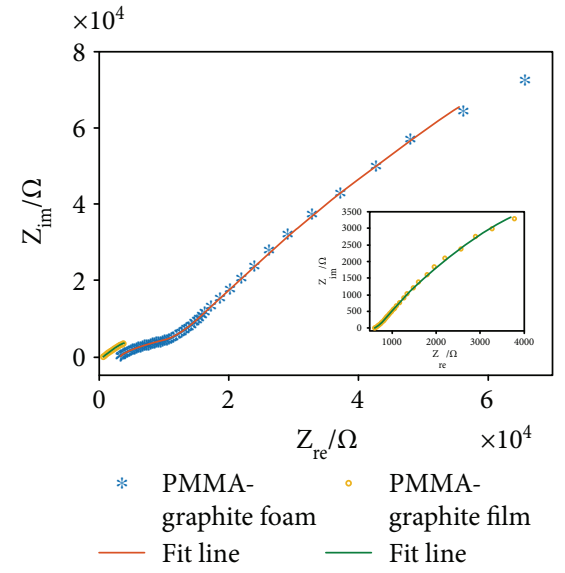

(a)

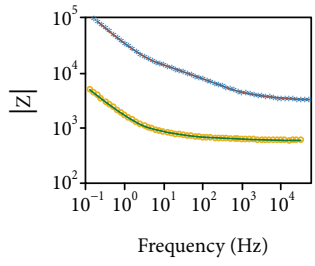

(b)

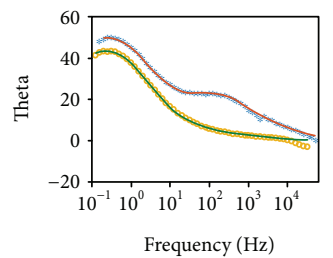

(c)

Figure 3: (a) Nyquist and (b) impedance Bode plot and (c) phase Bode plot of PMMA_G film and PMMA_F_G in 0.1 M KCl. Frequency swept from $31,600 \mathrm{~Hz}$ to $0.1 \mathrm{~Hz}$ at $0 \mathrm{~V}$ in a $0.1 \mathrm{M} \mathrm{KCl}$ solution.

influence of the porosity of the samples in the sensing properties of PMMA/graphite composites.

Figure 2(a) shows the internal structure of the PMMA foam (PMMA_F) where a homogeneous microporous structure with an average pore diameter of $2 \mu \mathrm{m}$ was observed. The image of the foam surface (Figure 2(b)) showed larger pores with irregular shapes and sizes with an average diameter of $7 \mu \mathrm{m}$. When PMMA foam was doped with graphite (PMMA_F_G), the internal porous structure changed. Large pores with $100 \mu \mathrm{m}$ diameter were accompanied by many small pores with an average diameter of $12 \mu \mathrm{m}$ (Figure 2(c)). It is also noticeable that the pores were more irregular in shape than those observed in the undoped PMMA_F. This effect can be attributed to the presence of the graphite flakes that modify the foaming process. The surface structure changed drastically in the presence of graphite, and a profusion of small pores of about $4 \mu \mathrm{m}$ diameter (Figure 2(d)) was observed.

\subsection{Electrochemical Impedance Spectroscopy (EIS)} Characterization. Electrochemical impedance spectroscopy (EIS) was used to study the changes in the electrochemical properties of PMMA induced by the insertion of graphite and by the foaming.

As expected, the Nyquist plots of nonfoamed PMMA and foamed PMMA_F immersed in $0.1 \mathrm{M} \mathrm{KCl}$ showed vertical straight lines, confirming that undoped samples behaved as insulators.

When graphite was added to the structure of a PMMA film (PMMA_G) or a PMMA foam (PMMA_F_G), samples became conductive and the Nyquist diagram (Figure 3(a)) revealed two unfinished capacitive loops. The semicircle in the high frequency region showed a smaller radius than the large arc observed in the low frequency region. As observed in Figure 3(a), the radii increased in foamed samples. Given that radii of the semicircles are related to the efficiency of the charge transfer, it can be concluded that the electron transfer resistance was higher in the foamed sample. In good

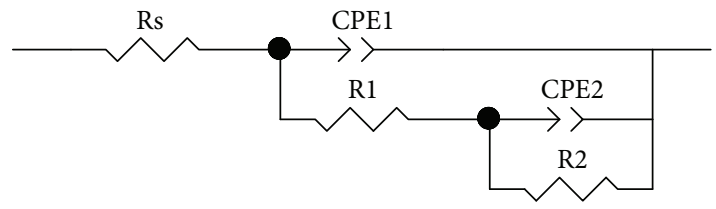

FIGURE 4: Equivalent electrical circuit used to simulate the response of the samples where Rs is the solution resistance, CPE1 is a first constant phase element, R1 is a first resistance, CPE2 is a second constant phase element, and $\mathrm{R} 2$ is a second resistance.

accordance, the Bode plots showed that the impedance modulus of the foamed PMMA_F_G was more than one order of magnitude larger than in the nonfoamed PMMA_G (Figures 3(b) and 3(c)).

In order to calculate the charge transfer resistance, the impedance values were fitted to the electrical circuit shown in Figure 4. In the proposed model, two constant phase elements CPE (representing a nonideal capacitive response of the interface material solution) and two resistances were used. The depression in the Nyquist semicircle and the phase angle of capacitor different from $-90^{\circ}$ are an indication of this non-pure capacitive behavior. The impedance of a CPE element was defined as:

$$
Z_{\mathrm{CPE}}=\frac{1}{C(j \omega)^{n}}
$$

where $C$ is a parameter numerically equal to the admittance at $\omega=1 \mathrm{rad} \cdot \mathrm{s}^{-1}, j$ is the imaginary unit, $\omega$ is the frequency, and $n$ is the phase shift. When $n=1$ the CPE describes an ideal capacitor, when $n=0$ is an ideal resistor and, when $n \approx 0.5$ is a finite-Warburg element accounting for diffusion of mobile charge. In practice, $n$ is in the range of zero to one, and $C$ can be approximately converted into a capacitance.

The results are presented in Table 1. Chi-squared $\left(\chi^{2}\right)$ values were used to evaluate the quality of fitting. The 
TABLE 1: Analytical data obtained from the impedance spectroscopy measurements.

\begin{tabular}{lccccccc}
\hline $\mathrm{Rs}\left(\Omega \cdot \mathrm{cm}^{2}\right)$ & $\mathrm{C}_{\mathrm{CPE} 1}\left(\mathrm{~s}^{\mathrm{n}} \Omega^{-1} \cdot \mathrm{cm}^{-2}\right)$ & $\mathrm{n}_{\mathrm{CPE} 1}$ & $\mathrm{R} 1\left(\Omega \cdot \mathrm{cm}^{2}\right)$ & $\mathrm{C}_{\mathrm{CPE1}}\left(\mathrm{s}^{\mathrm{n}} \Omega^{-1} \cdot \mathrm{cm}^{-2}\right)$ & $\mathrm{n}_{\mathrm{CPE} 2}$ & $\mathrm{R} 2\left(\Omega \cdot \mathrm{cm}^{2}\right)$ & $\chi^{2}\left(10^{-4}\right)$ \\
\hline PMMA_G & & & & & & & \\
610 & $6.7 \cdot 10^{-5}$ & 0.67 & 205.3 & $1.5 \cdot 10^{-4}$ & 0.70 & 15270 & 3.7 \\
PMMA_F_G & & & & & & & \\
3151 & $3.4 \cdot 10^{-6}$ & 0.58 & 13974 & $6.8 \cdot 10^{-6}$ & 0.75 & 418250 & 4.6 \\
\hline
\end{tabular}

obtained values were in the range of $10^{-4}$, indicating the suitability of the circuit.

Table 1 shows that $R 1$ values were always significantly lower than $R 2$. The addition of $R 1$ and $R 2$ (considered as the electron transfer resistance) clearly increased in the foamed sample and the CPE-C values were lower for the foamed sample. The decrease in the capacitance and the increase in the resistance was induced by porosity.

Moreover, the impedance behavior indicated that the electron transfer resistance was higher in the foamed sample due to the air trapped into the foam micropores, increasing thus the resistivity [44]. In spite of this, the conductivity was high enough to use the foams as highly porous electrodes where the increase in the porosity and the subsequent higher superficial area can be an advantage.

3.3. Sensing Behavior. Detection of Antioxidants. Once the structure and the conductivity were characterized by SEM and EIS, graphite-doped samples were used as working electrodes in an electrochemical cell for the detection of CT and $\mathrm{HQ}$, two of the most interesting antioxidants found in foods and beverages.

3.3.1. Catechol and Hydroquinone Determination. Figures 5(a) and 5(b) show the square wave voltammetry (SWV) recorded for increasing catechol concentrations using nonfoamed and foamed sensors. As observed, the foaming process induced important differences in the electrochemical responses. In the case of PMMA_G, low catechol concentrations produced a single redox peak at about $+0.35 \mathrm{~V}$ (peak 1 ); as the concentration of catechol increased, a second peak appeared at higher potentials $(+0.75 \mathrm{~V})$ (peak 2), which is usually attributed to the dimerization or polymerization of phenols at the electrode surface $[45,46]$. In contrast, the response of the foamed PMMA_F_G to catechol was characterized by a single peak centered at around $+0.35 \mathrm{~V}$, and polymerization was not observed. The absence of polymerization is an advantage because polymerization is an important cause of electrode fouling.

SWVs recorded at increasing hydroquinone concentrations are shown in Figures 5(c) and 5(d) for PMMA_G and PMMA_F_G sensors, respectively. In the case of the nonfoamed electrode, two peaks were observed even at low concentrations: the first peak appeared at $+0.15 \mathrm{~V}$ (peak 1) and the second one appeared at $+0.55 \mathrm{~V}$ (peak 2). When the concentration increased, a new peak at about $+0.75 \mathrm{~V}$ was observed as a shoulder. In the voltammograms registered using the foamed PMMA_F_G, the first peak was centered about $+0.12 \mathrm{~V}$ (peak 1). This time, the polymerization peak was observed at high concentrations (peak 2) and shifted to higher potentials as the concentration increased, reaching a final value of $+0.9 \mathrm{~V}$.

According to these results, the nonfoamed and the foamed electrodes have different electrochemical behaviors. Thus, the oxidation mechanism for catechol and hydroquinone on both surfaces is different. In addition, foamed electrodes prevent polymerization processes that can cause fouling of the electrodes.

Limits of detection (LOD) were calculated from the calibration curves constructed by representing the current intensity of the redox peaks versus catechol or hydroquinone concentrations. It has to be noticed that in some cases, two linear ranges were observed. Table 2 shows the linear ranges, the analytical linear calibration curves, the analytical parameters obtained from the curves including the regression coefficients $\left(R^{2}\right)$, the residual standard errors $\left(\mathrm{s}_{\mathrm{yx}}\right)$, and the LODs calculated form the curves using R-project as the program for statistical computing.

According to data listed in Table 2, important advantages can be observed in the foamed samples: linear ranges are larger in the foamed sensors, the residual standard errors are smaller, and LODs are lower. For instance, using PMMA_G, limits of detection for CT of $0.47 \mathrm{mM}$ and $0.29 \mathrm{mM}$ were calculated for the first and second oxidation peak, respectively, with a probability of false positive $(\alpha)$ and false negative $(\beta)$ of 0.05 . In contrast, LODs calculated using PMMA_F_G were $0.06 \mathrm{mM}$ and $0.17 \mathrm{mM}$. This means that LODs are clearly diminished, mainly in the case of the first linear range, where a decrease of one order of magnitude was observed.

Similar results were obtained for HQ determination. In this case, the decrease observed in the LODs calculated using peak 1 was more marked than in peak 2, and a LOD of $0.12 \mathrm{mM}$ was attained for the foamed sensor.

3.3.2. Simultaneous Determination of Hydroquinone and Catechol. Hydroquinone and catechol are two isomers and therefore, their oxidation peaks occur at very close potentials. This makes difficult the simultaneous assessment of both compounds. According to the results shown in Figure 5, the oxidation peak of CT is around $+0.35 \mathrm{~V}$ and the oxidation peak for $\mathrm{HQ}$ is around $+0.15 \mathrm{~V}$. In addition, the degree of polymerization in foamed sensors is smaller. These results point to the possible advantage of PMMA foamed sensors to discriminate between both isomers, allowing the simultaneous assessment of both components.

In order to evaluate the capability of our foamed sensors to discriminate between both isomers, voltammograms were registered in solutions containing a fixed concentration of hydroquinone $(2 \mathrm{mM})$ and increasing concentrations of 


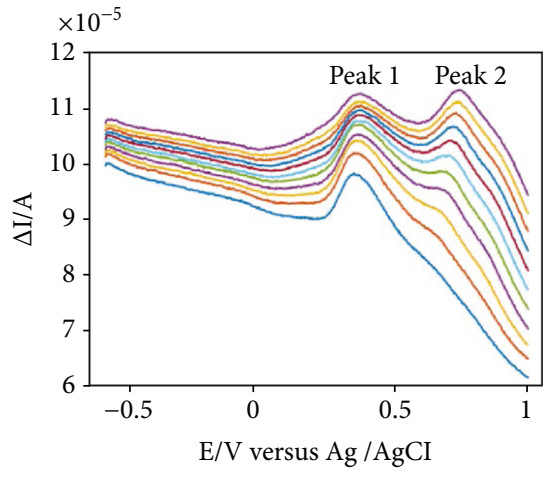

(a)

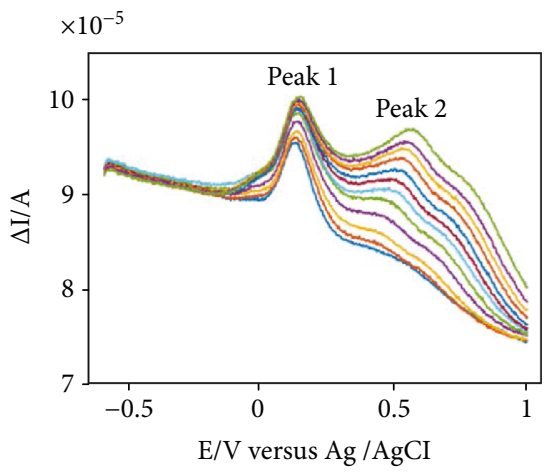

(c)

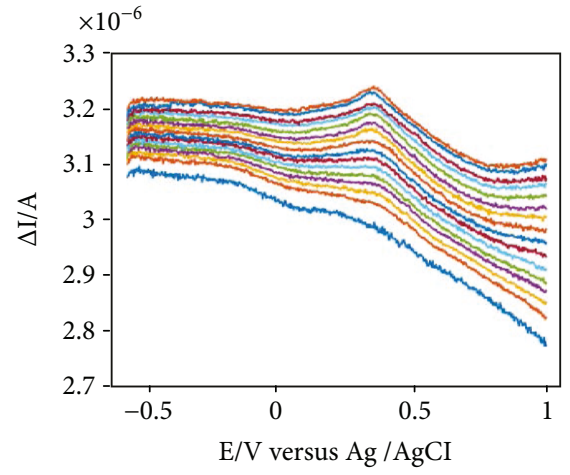

(b)

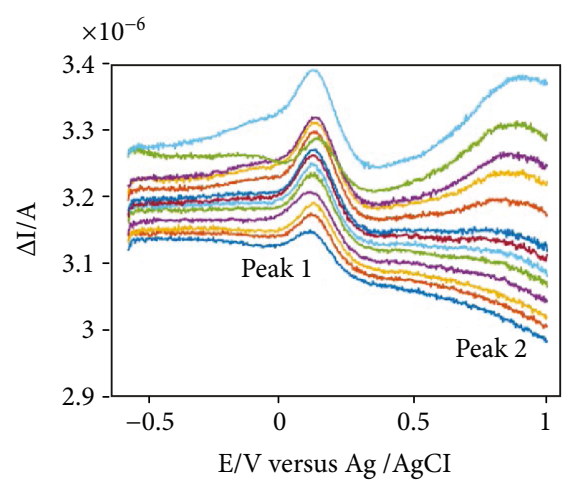

(d)

FIgure 5: SWV of (a) PMMA_G immersed in CT concentrations from 0 to $2.91 \mathrm{mM}$; (b) PMMA_F_G immersed in CT concentrations from 0 to $1.67 \mathrm{mM}$; (c) PMMA_G immersed in HQ concentrations from 0 to $3.15 \mathrm{mM}$; and (d) PMMA_F_G immersed in HQ concentrations from 0 to $2.68 \mathrm{mM}$. 0.1 $\mathrm{M} \mathrm{KCl}$ was used as supporting electrolyte.

TABLE 2: Analytical data obtained from the calibration curves.

\begin{tabular}{|c|c|c|c|c|c|c|}
\hline & & Linear range $(\mathrm{mM})$ & Calibration curves & $R^{2}$ & $\mathrm{~s}_{\mathrm{yx}}$ & $\mathrm{LOD}(\mathrm{mM})$ \\
\hline \multicolumn{7}{|c|}{ PMMA_G } \\
\hline \multirow{3}{*}{ CT } & Peak 1 & $0.99-2.68$ & $y=1.00 \cdot 10^{-4}+3.92 \cdot 10^{-6} x$ & 0.9812 & $3.20 \cdot 10^{-7}$ & 0.47 \\
\hline & Peak 2 & $0.50-1.72$ & $y=6.77 \cdot 10^{-5}+1.99 \cdot 10^{-5} x$ & 0.9890 & $1.10 \cdot 10^{-6}$ & 0.29 \\
\hline & Peak 2 & $1.96-2.91$ & $y=8.58 \cdot 10^{-5}+9.39 \cdot 10^{-6} x$ & 0.9906 & $3.44 \cdot 10^{-7}$ & 0.53 \\
\hline \multirow{2}{*}{ HQ } & Peak 1 & $1.23-3.15$ & $\mathrm{y}=9.77 \cdot 10^{-5}+8.73 \cdot 10^{-7} \mathrm{x}$ & 0.9786 & $8.85 \cdot 10^{-8}$ & 0.62 \\
\hline & Peak 2 & $0.50-2.44$ & $y=7.86 \cdot 10^{-5}+6.39 \cdot 10^{-6} x$ & 0.9982 & $1.85 \cdot 10^{-7}$ & 0.13 \\
\hline \multicolumn{7}{|c|}{$\overline{P M M A \_F \_G}$} \\
\hline \multirow{2}{*}{$\mathrm{CT}$} & Peak 1 & $0.15-0.45$ & $y=2.94 \cdot 10^{-6}+3.44 \cdot 10^{-7} x$ & 0.9931 & $3.09 \cdot 10^{-9}$ & 0.06 \\
\hline & Peak 1 & $0.45-1.67$ & $y=3.04 \cdot 10^{-6}+1.19 \cdot 10^{-7} x$ & 0.9921 & $4.30 \cdot 10^{-9}$ & 0.17 \\
\hline \multirow{2}{*}{ HQ } & Peak 1 & $0.37-1.11$ & $y=3.09 \cdot 10^{-6}+1.59 \cdot 10^{-7} x$ & 0.9941 & $3.26 \cdot 10^{-9}$ & 0.12 \\
\hline & Peak 2 & $0.37-2.68$ & $y=2.95 \cdot 10^{-6}+1.64 \cdot 10^{-7} x$ & 0.9991 & $3.55 \cdot 10^{-9}$ & 0.09 \\
\hline
\end{tabular}

catechol, from 0.26 to $1.92 \mathrm{mM}$. The response of the PMMA_G sensor immersed in a solution that contains $2 \mathrm{mM}$ of hydroquinone and increasing concentrations of catechol (Figure 6(a)) showed a peak at about $+0.70 \mathrm{~V}$ that was growing progressively with the catechol concentration. This peak could be used to build a robust calibration curve in function of the catechol concentration with a good regression coefficient and low residual standard error (Table 3 collects the regression parameters). The calibration curve showed a linear range, from 0.61 to $1.92 \mathrm{mM}$. A LOD of $0.34 \mathrm{mM}$ was obtained from the curve with a probability of false positive $(\alpha)$ and false negative $(\beta)$ of 0.05 . Similarly, the response for the PMMA_F_G towards hydroquinone $2 \mathrm{mM}$ and increasing amounts of catechol also showed a peak at $+0.25 \mathrm{~V}$ that increased linearly with the catechol concentration. In this case, the linear range was larger and ranged from 0.37 to $1.69 \mathrm{mM}$. Carrying out a robust regression, it was possible to obtain a calibration curve with a good regression 


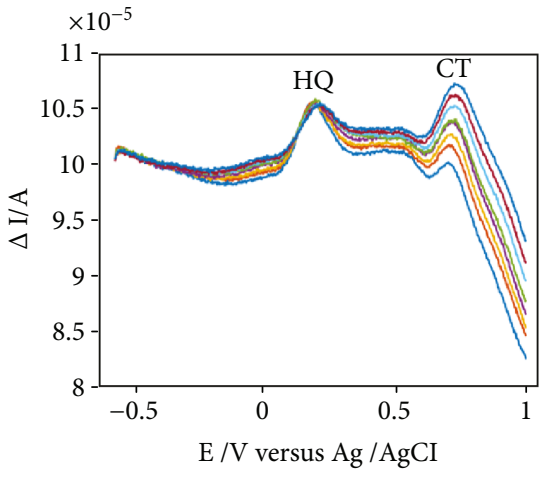

(a)

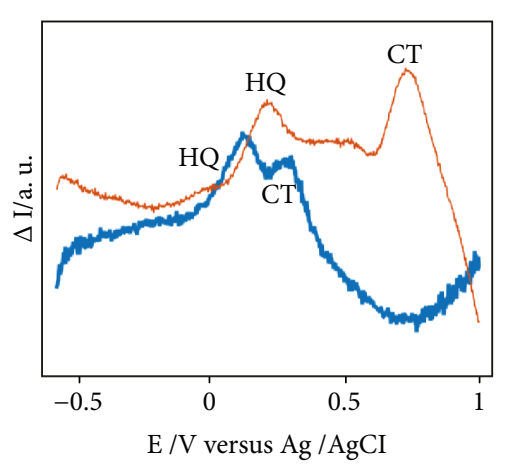

(b)

FIGURE 6: (a) SWV recorded using PMMA_G for increasing concentrations of catechol from 0.61 to $1.92 \mathrm{mM}$ in the presence of $2 \mathrm{mM}$ hydroquinone in $0.1 \mathrm{M} \mathrm{KCl}$ as supporting electrolyte, and (b) comparison for SWV recorded for PMMA_G (red line) and PMMA_F_G (blue line) for $1.92 \mathrm{mM}$ of catechol in the presence of $2 \mathrm{mM}$ hydroquinone in $0.1 \mathrm{M} \mathrm{KCl}$ as supporting electrolyte.

TABle 3: Analytical data obtained from the calibration curves of mixtures CT/HQ.

\begin{tabular}{lcccc}
\hline & Linear range $(\mathrm{mM})$ & Regression curve & $R^{2}$ & $\mathrm{~s}_{\mathrm{yx}}$ \\
\hline PMMA_G & & & & $\mathrm{LOD}(\mathrm{mM})$ \\
CT & $0.61-1.92$ & $\mathrm{y}=9.73 \cdot 10^{-5}+5.38 \cdot 10^{-6} \mathrm{x}$ & 0.9806 & $3.32 \cdot 10^{-7}$ \\
PMMA_F_G & & & & 0.34 \\
CT & $0.37-1.69$ & $\mathrm{y}=3.28 \cdot 10^{-6}+7.82 \cdot 10^{-8} \mathrm{x}$ & 0.9804 & $4.67 \cdot 10^{-9}$ \\
\hline
\end{tabular}

coefficient and low residual standard error (Table 3 summarizes the regression parameters). Furthermore, this calibration curve could be used to calculate a limit of detection of $0.27 \mathrm{mM}$, with a probability of false positive $(\alpha)$ and false negative $(\beta)$ of 0.05 .

According to these results, both the PMMA_G and the PMMA_G_F sensors can be used to assess catechol in presence of hydroquinone with very close limits of detection. However, foamed sensors show two important advantages. First, the foamed sensor has a larger linear range. But the main advantage is the high electrocatalytic activity of the foamed porous electrode that caused an important shift of the catechol peak from $+0.70 \mathrm{~V}$ to $+0.25 \mathrm{~V}$ that can reduce considerably the potential that needs to be applied in the working conditions of amperometry. This electrocatalytic effect has been illustrated in Figure 6(b), where the SWV recorded for the same concentration of catechol and hydroquinone (1.92 and $2 \mathrm{mM}$, resp.) is displayed.

3.4. Dynamic Properties. Once the different electrocatalytic properties of PMMA electrodes were established, the dynamic properties were analyzed by registering cyclic voltammograms at increasing scan rates. The dynamic properties for our PMMA_G and PMMA_F_G sensors were characterized in a catechol solution of $10^{-\overline{3}} \mathrm{M}$ in $0.1 \mathrm{M} \mathrm{KCl}$ as supporting electrolyte from $-0.50 \mathrm{~V}$ to $+1.50 \mathrm{~V}$ at scan rates from 0.1 to $0.3 \mathrm{~V} / \mathrm{s}$.

Representing the current intensity of the reduction peak (at around $+0.40 \mathrm{~V}$ ) versus the square root of the scan rate,
TABle 4: Dynamic character. Analytical data obtained from the dynamic properties using a solution that contains catechol $10^{-3} \mathrm{M}$ and $\mathrm{KCl} 0.1 \mathrm{M}$ as supporting electrolyte.

\begin{tabular}{lcc}
\hline \multicolumn{1}{c}{ Regression curve } & $R^{2}$ & $\mathrm{~s}_{\mathrm{yx}}$ \\
\hline PMMA_G & & \\
CT $\quad \mathrm{y}=4.19 \cdot 10^{-5}-4.31 \cdot 10^{-4} \mathrm{x}$ & 0.9994 & $8.20 \cdot 10^{-7}$ \\
PMMA_F_G & & \\
CT $\quad \mathrm{y}=-2.30 \cdot 10^{-6}-1.29 \cdot 10^{-5} \mathrm{x}$ & 0.9951 & $7.17 \cdot 10^{-8}$ \\
\hline
\end{tabular}

a linear relationship was obtained. Data could be adjusted to the Randles-Sevcik equation (2), indicating a quasireversible process controlled by diffusion [43] (Table 4).

$$
i_{\mathrm{p}}=0.4463 \cdot n \cdot F \cdot A \cdot C \cdot\left(\frac{n F v D}{R T}\right)^{1 / 2}
$$

Where $i_{\mathrm{p}}$ is the peak current, $n$ is the electron number transferred in the redox process, $F$ is the Faraday constant, $R$ is the gas constant, $T$ is the temperature, $A$ is the area of the working electrode, $C$ is the concentration for the electroactive species, $D$ is the diffusion coefficient for the electroactive species, and $v$ is the scan rate.

As observed in Table 4, the slopes of the curves were one order of magnitude lower in the foamed sensor, indicating that kinetics was clearly modified by the presence of pores in the structure and a foamed surface. 


\section{Conclusions}

Catechol (CT), hydroquinone (HQ), and their mixtures have been successfully analyzed at nonenzymatic electrodes based on PMMA doped with graphite. The porous structure of foamed electrodes induced important advantages including reduction of fouling effects, excellent electrocatalytic activity, and decrease in the limits of detection of CT and HQ that were one order of magnitude lower in foamed electrodes. In the case of mixtures, the electrocatalytic effect played an important role and LODs obtained were in the range of $10^{-4} \mathrm{M}$. These results confirmed the promising capabilities of foamed polymers as sensitive materials for electrochemical sensors.

\section{Data Availability}

Data are available on request to Maria Luz RodriguezMendez (mluz@eii.uva.es).

\section{Conflicts of Interest}

The authors declare no conflict of interest.

\section{Acknowledgments}

This paper is dedicated to Professor Jose Antonio de Saja, who passed away on November 20, 2017. This work was supported by MINECO-FEDER (AGL2015-67482-R) and the Junta de Castilla y Leon-FEDER (VA-011U16). C. Fernandez-Blanco would also like to thank Junta de Castilla y León and FEDER for her postdoctoral grant (VA-011U16).

\section{Supplementary Materials}

Supplementary information present two figures with the calibration curves described in the manuscript: Figure S1: calibration curves for catechol obtained using PMMA_G and PMMA_F_G and the calibration curves for hydroquinone obtained using PMMA_G and PMMA_F_G. Figure S2: calibration curves for catechol obtained using PMMA_G and PMMA_F_G in the presence of $2 \mathrm{mM}$ of hydroquinone. (Supplementary Materials)

\section{References}

[1] G. Bartosz, Food Oxidants and Antioxidants: Chemical, Biological, and Functional Properties, Z. E. Sikorski, Ed., CRC Press, Boca Raton, FL, USA, 2013.

[2] W. Gao and C. Legido-Quigley, "Fast and sensitive high performance liquid chromatography analysis of cosmetic creams for hydroquinone, phenol and six preservatives," Journal of Chromatography A, vol. 1218, no. 28, pp. 4307-4311, 2011.

[3] G. Marrubini, E. Calleri, T. Coccini, A. F. Castoldi, and L. Manzo, "Direct analysis of phenol, catechol and hydroquinone in human urine by coupled-column HPLC with fluorimetric detection," Chromatographia, vol. 62, no. 1-2, pp. 25-31, 2005.

[4] H. Cui, C. He, and G. Zhao, "Determination of polyphenols by high-performance liquid chromatography with inhibited chemiluminescence detection," Journal of Chromatography A, vol. 855, no. 1, pp. 171-179, 1999.

[5] D. H. Bremner, A. E. Burgess, D. Houllemare, and K.-C. Namkung, "Phenol degradation using hydroxyl radicals generated from zero-valent iron and hydrogen peroxide," Applied Catalysis B: Environmental, vol. 63, no. 1-2, pp. 15-19, 2006.

[6] S. C. Moldoveanu and M. Kiser, "Gas chromatography/mass spectrometry versus liquid chromatography/fluorescence detection in the analysis of phenols in mainstream cigarette smoke," Journal of Chromatography A, vol. 1141, no. 1, pp. 90-97, 2007.

[7] A. Nenov, S. Mukamel, M. Garavelli, and I. Rivalta, "Twodimensional electronic spectroscopy of benzene, phenol, and their dimer: an efficient first-principles simulation protocol," Journal of Chemical Theory and Computation, vol. 11, no. 8, pp. 3755-3771, 2015.

[8] L. Zhao, B. Lv, H. Yuan, Z. Zhou, and D. Xiao, "A sensitive chemiluminescence method for determination of hydroquinone and catechol," Sensors, vol. 7, no. 4, pp. 578-588, 2007.

[9] P. Nagaraja, R. A. Vasantha, and K. R. Sunitha, "A sensitive and selective spectrophotometric estimation of catechol derivatives in pharmaceutical preparations," Talanta, vol. 55, no. 6, pp. 1039-1046, 2001.

[10] M. F. Pistonesi, M. S. Di Nezio, M. E. Centurión, M. E. Palomeque, A. G. Lista, and B. S. Fernández Band, "Determination of phenol, resorcinol and hydroquinone in air samples by synchronous fluorescence using partial least-squares (PLS)," Talanta, vol. 69, no. 5, pp. 1265-1268, 2006.

[11] M. Bosco, M. P. Callao, and M. S. Larrechi, "Resolution of phenol, and its di-hydroxyderivative mixtures by excitation-emission fluorescence using MCR-ALS: application to the quantitative monitoring of phenol photodegradation," Talanta, vol. 72, no. 2, pp. 800-807, 2007.

[12] H. Cui, Q. Zhang, A. Myint, X. Ge, and L. Liu, "Chemiluminescence of cerium(IV)-rhodamine 6G-phenolic compound system," Journal of Photochemistry and Photobiology A: Chemistry, vol. 181, no. 2-3, pp. 238-245, 2006.

[13] J. McCall, C. Alexander, and M. M. Richter, "Quenching of electrogenerated chemiluminescence by phenols, hydroquinones, catechols, and benzoquinones," Analytical Chemistry, vol. 71, no. 13, pp. 2523-2527, 1999.

[14] J. McCall and M. M. Richter, "Phenol substituent effects on electrogenerated chemiluminescence quenching," Analyst, vol. 125 , no. 3, pp. 545-548, 2000.

[15] N. Guan, Z. Zeng, Y. Wang, E. Fu, and J. Cheng, “Open tubular capillary electrochromatography in fused-silica capillaries chemically bonded with macrocyclic dioxopolyamine," Analytica Chimica Acta, vol. 418, no. 2, pp. 145-151, 2000.

[16] H. Lü, J. Wang, X. Wang, X. Wu, X. Lin, and Z. Xie, "Singlestep preparation and characterization of polymeric monolith for pressurized capillary electrochromatography of typical homologs," Journal of Separation Science, vol. 30, no. 17, pp. 2993-2999, 2007.

[17] S. Sakthinathan, S. Palanisamy, S.-M. Chen, P.-S. Wu, L. Yao, and B.-S. Lou, "Electrochemical detection of phenol in industrial pollutant absorbed molecular sieves by electrochemically activated screen printed carbon electrode," International Journal of Electrochemical Science, vol. 10, pp. 3319-3328, 2015. 
[18] K. Chen, Z. L. Zhang, Y. M. Liang, and W. Liu, "A graphenebased electrochemical sensor for rapid determination of phenols in water," Sensors, vol. 13, no. 5, pp. 6204-6216, 2013.

[19] M. F. Barroso, N. de-los-Santos-Álvarez, C. Delerue-Matos, and M. B. P. P. Oliveira, "Towards a reliable technology for antioxidant capacity and oxidative damage evaluation: electrochemical (bio)sensors," Biosensors and Bioelectronics, vol. 30, no. 1, pp. 1-12, 2011.

[20] C. Apetrei, I. M. Apetrei, J. A. SajaDe, and M. L. RodriguezMendez, "Carbon paste electrodes made from different carbonaceous materials: application in the study of antioxidants," Sensors, vol. 11, no. 2, pp. 1328-1344, 2011.

[21] F. Matemadombo, C. Apetrei, T. Nyokong, M. L. RodríguezMéndez, and J. A. de Saja, "Comparison of carbon screenprinted and disk electrodes in the detection of antioxidants using CoPc derivatives," Sensors and Actuators B: Chemical, vol. 166-167, pp. 457-466, 2012.

[22] A. J. Saleh Ahammad, S. Sarker, M. A. Rahman, and J.-J. Lee, "Simultaneous determination of hydroquinone and catechol at an activated glassy carbon electrode," Electroanalysis, vol. 22, no. 6, pp. 694-700, 2010.

[23] W. Zhang, J. Zheng, Z. Lin et al., "Highly sensitive simultaneous electrochemical determination of hydroquinone, catechol and resorcinol based on carbon dot/reduced graphene oxide composite modified electrodes," Analytical Methods, vol. 7, no. 15, pp. 6089-6094, 2015.

[24] M. Li, F. Ni, Y. Wang et al., "Sensitive and facile determination of catechol and hydroquinone simultaneously under coexistence of resorcinol with a $\mathrm{Zn} / \mathrm{Al}$ layered double hydroxide film modified glassy carbon electrode," Electroanalysis, vol. 21, no. 13, pp. 1521-1526, 2009.

[25] T. Gan, J. Sun, K. Huang, L. Song, and Y. Li, “A graphene oxide-mesoporous $\mathrm{MnO}_{2}$ nanocomposite modified glassy carbon electrode as a novel and efficient voltammetric sensor for simultaneous determination of hydroquinone and catechol," Sensors and Actuators B: Chemical, vol. 177, pp. 412-418, 2013.

[26] H. Du, J. Ye, J. Zhang, X. Huang, and C. Yu, “A voltammetric sensor based on graphene-modified electrode for simultaneous determination of catechol and hydroquinone," Journal of Electroanalytical Chemistry, vol. 650, no. 2, pp. 209-213, 2011.

[27] M. Amiri, S. Ghaffari, A. Bezaatpour, and F. Marken, "Carbon nanoparticle-chitosan composite electrode with anion, cation, and neutral binding sites: dihydroxybenzene selectivity," Sensors and Actuators B: Chemical, vol. 162, no. 1, pp. 194-200, 2012.

[28] Q. Guo, J. Huang, P. Chen, Y. Liu, H. Hou, and T. You, "Simultaneous determination of catechol and hydroquinone using electrospun carbon nanofibers modified electrode," Sensors and Actuators B: Chemical, vol. 163, no. 1, pp. 179-185, 2012.

[29] Z. Huo, Y. Zhou, Q. Liu, X. He, Y. Liang, and M. Xu, "Sensitive simultaneous determination of catechol and hydroquinone using a gold electrode modified with carbon nanofibers and gold nanoparticles," Microchimica Acta, vol. 173, no. 1-2, pp. 119-125, 2011.

[30] L. Alshahrani, X. Li, H. Luo et al., "The simultaneous electrochemical detection of catechol and hydroquinone with $\left[\mathrm{Cu}\left(\mathrm{Sal}-\beta\right.\right.$-Ala) $\left.(3,5-\mathrm{DMPz})_{2}\right] /$ SWCNTs/GCE," Sensors, vol. 14, no. 12, pp. 22274-22284, 2014.

[31] C. Medina-Plaza, C. García-Cabezón, C. García-Hernández et al., "Analysis of organic acids and phenols of interest in the wine industry using Langmuir-Blodgett films based on functionalized nanoparticles," Analytica Chimica Acta, vol. 853, pp. 572-578, 2015.

[32] E. G. R. Fernandes, L. C. Brazaca, M. L. Rodríguez-Mendez, J. A. Sajade, and V. Zucolotto, "Immobilization of lutetium bisphthalocyanine in nanostructured biomimetic sensors using the LbL technique for phenol detection," Biosensors and Bioelectronics, vol. 26, no. 12, pp. 4715-4719, 2011.

[33] C. Medina-Plaza, L. N. Furini, C. J. L. Constantino, J. A. de Saja, and M. L. Rodriguez-Mendez, "Synergistic electrocatalytic effect of nanostructured mixed films formed by functionalised gold nanoparticles and bisphthalocyanines," Analytica Chimica Acta, vol. 851, pp. 95-102, 2014.

[34] W. Lu, X. Qin, A. M. Asiri, A. O. Al-Youbi, and X. Sun, "Ni foam: a novel three-dimensional porous sensing platform for sensitive and selective nonenzymatic glucose detection," Analyst, vol. 138, no. 2, pp. 417-420, 2013.

[35] Q. Xiao, X. Wang, and S. Huang, "Facile synthesis of $\mathrm{Ni}(\mathrm{OH})_{2}$ nanowires on nickel foam via one step low-temperature hydrothermal route for non-enzymatic glucose sensor," Materials Letters, vol. 198, pp. 19-22, 2017.

[36] X. Wang, X. Guo, J. Chen et al., "Au nanoparticles decorated graphene/nickel foam nanocomposite for sensitive detection of hydrogen peroxide," Journal of Materials Science \& Technology, vol. 33, no. 3, pp. 246-250, 2017.

[37] H. Feng, Z. Huang, X. Lou, J. Li, and G. Hui, "Study of a sucrose sensor by functional cu foam material and its applications in commercial beverages," Food Analytical Methods, vol. 10, no. 2, pp. 407-418, 2017.

[38] C. Zhao, X. Wu, X. Zhang, P. Li, and X. Qian, "Facile synthesis of layered $\mathrm{CuS} / \mathrm{RGO} / \mathrm{CuS}$ nanocomposite on $\mathrm{Cu}$ foam for ultrasensitive nonenzymatic detection of glucose," Journal of Electroanalytical Chemistry, vol. 785, pp. 172-179, 2017.

[39] X. Liu, W. Yang, L. Chen, and J. Jia, “Three-dimensional copper foam supported $\mathrm{CuO}$ nanowire arrays: an efficient nonenzymatic glucose sensor," Electrochimica Acta, vol. 235, pp. 519-526, 2017.

[40] J. Pinto, J. A. Reglero-Ruiz, M. Dumon, and M. A. RodriguezPerez, "Temperature influence and $\mathrm{CO}_{2}$ transport in foaming processes of poly(methyl methacrylate)-block copolymer nanocellular and microcellular foams," The Journal of Supercritical Fluids, vol. 94, pp. 198-205, 2014.

[41] D. Miller and V. Kumar, "Microcellular and nanocellular solid-state polyetherimide (PEI) foams using sub-critical carbon dioxide II. Tensile and impact properties," Polymer, vol. 52, no. 13, pp. 2910-2919, 2011.

[42] S. Siripurapu, J. A. Coughlan, R. J. Spontak, and S. A. Khan, "Surface-constrained foaming of polymer thin films with supercritical carbon dioxide," Macromolecules, vol. 37, no. 26, pp. 9872-9879, 2004.

[43] A. J. Bard and L. R. Faulkner, Electrochemical Methods: Fundamentals and Applications, Wiley, New York, NY, USA, 2001.

[44] B. Q. Li and X. Lu, "The effect of pore structure on the electrical conductivity of Ti," Transport in Porous Media, vol. 87, no. 1, pp. 179-189, 2011.

[45] M. D. Ryan, A. Yueh, and W.-Y. Chen, "The electrochemical oxidation of substituted catechols," Journal of the Electrochemical Society, vol. 127, no. 7, pp. 1489-1495, 1980.

[46] F. Pospíšil, M. Hrubcová, and M. Cvikková, “Anodic oxidation of coumarie and caffeic acids and their effects on nitrate uptake and nitrate reducta se in Nicotia na tabacum cell suspension," Biologia Plantarum, vol. 29, no. 3, pp. 175-182, 1987. 


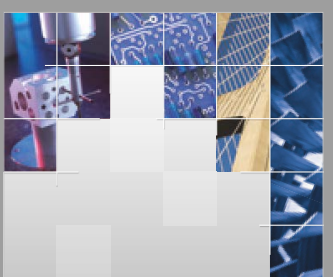

\section{Enfincering}
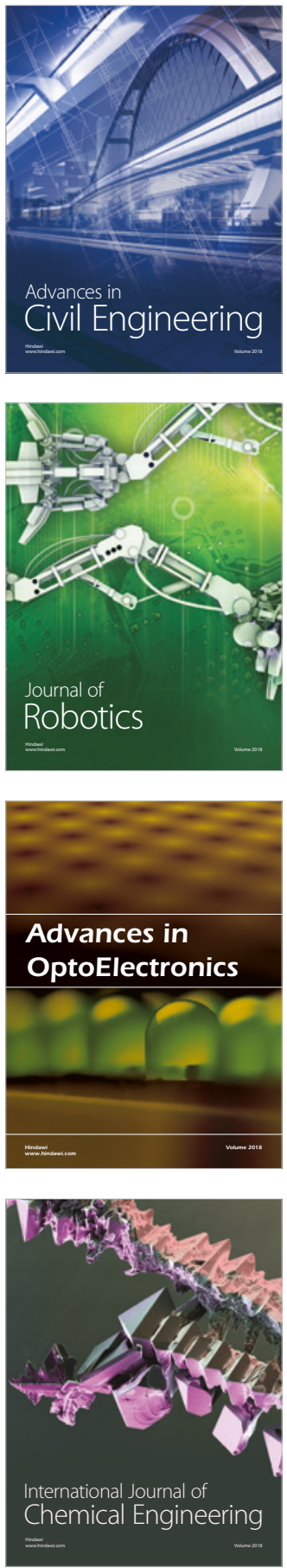

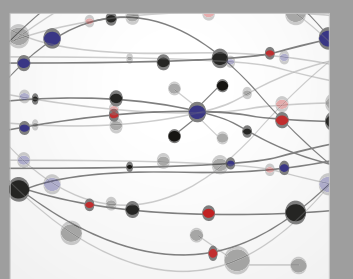

\section{Rotating \\ Machinery}

The Scientific World Journal

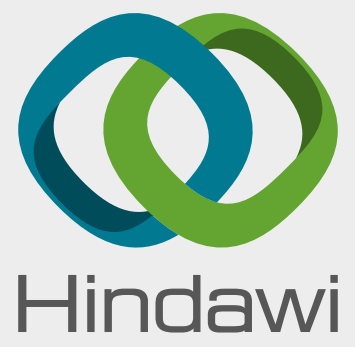

Submit your manuscripts at

www.hindawi.com
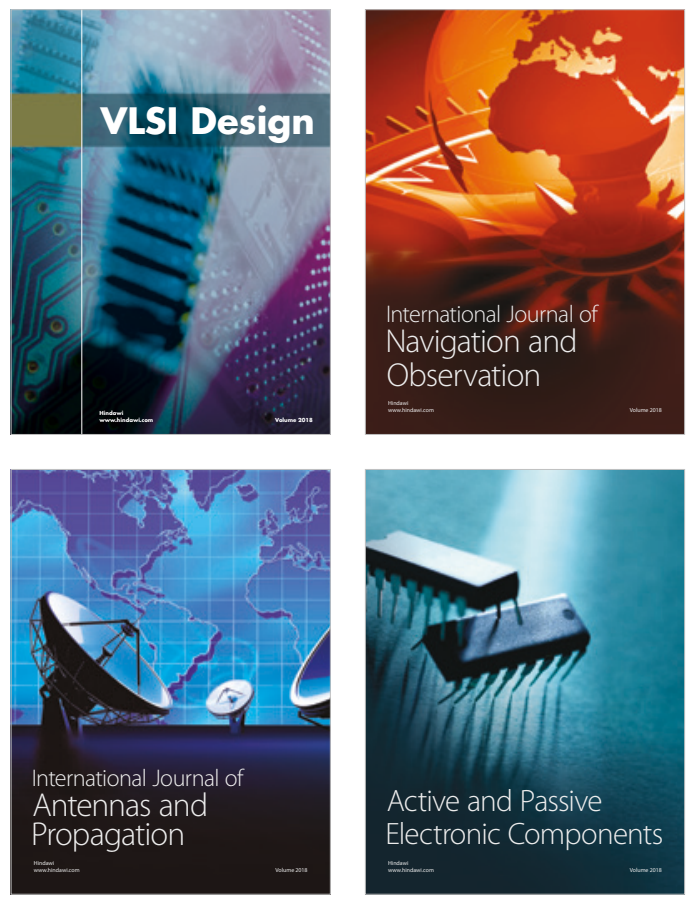
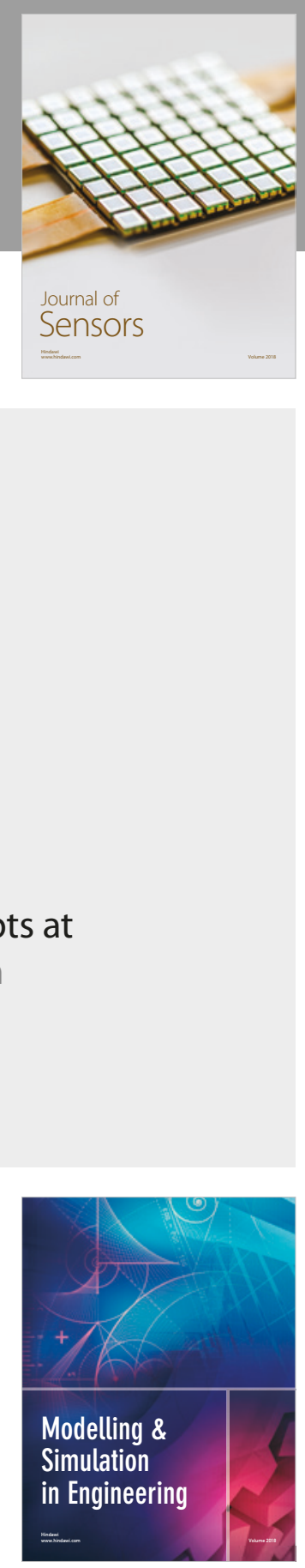

\section{Advances \\ Multimedia}
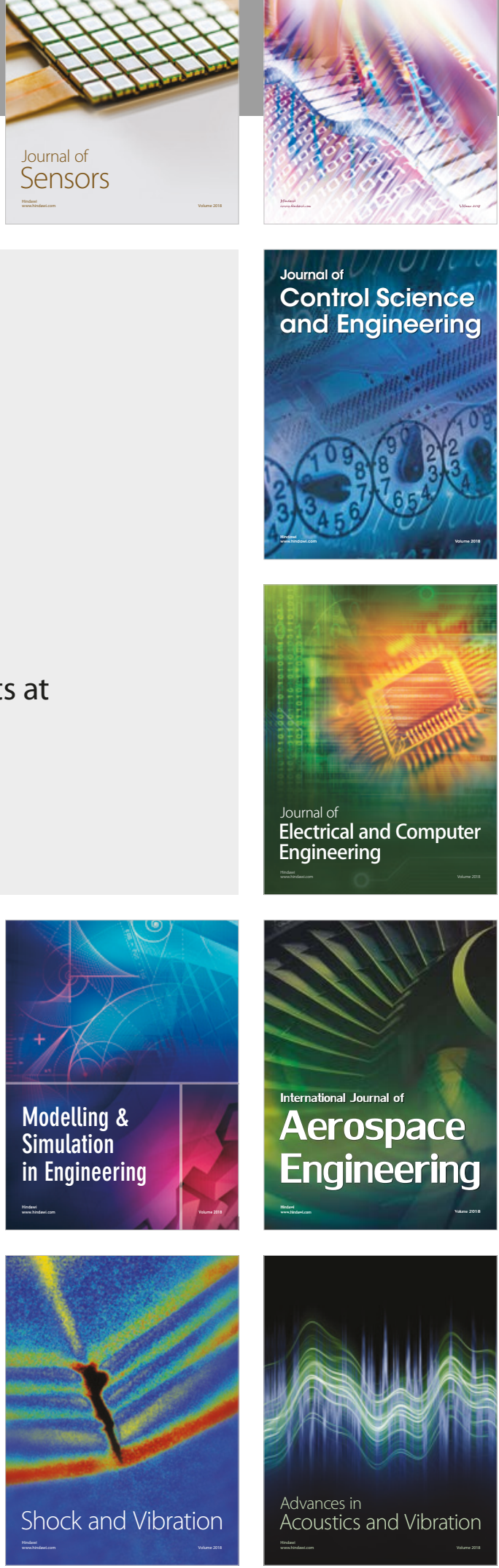